\title{
Rectifying effect in high-performance ballistic diode bridge with a unique design for thermal energy harvesting
}

\section{Dinh Cong Nguyen}

Sejong University

Minwook Kim

Sejong University

Muhammad Hussain

Sejong University

Van Huy Nguyen

Sejong University

Yeon-jae Lee

Sejong University

Dongwoon Kang

Sejong University

\section{Sunil Kumar}

Sejong University

Jongwan Jung

Sejong University

Yongho Seo ( $\square$ yseo@sejong.ac.kr)

Sejong University https://orcid.org/0000-0002-5695-5493

\section{Article}

Keywords: hBN encapsulated graphene, ballistic rectification, ballistic diode, energy harvesting, Johnson noise

Posted Date: May 17th, 2021

DOI: https://doi.org/10.21203/rs.3.rs-514739/v1

License: (c) (1) This work is licensed under a Creative Commons Attribution 4.0 International License.

Read Full License 


\section{Abstract}

The long mean free path close to a micrometer in encapsulated graphene enabled us to rectify currents ballistically at room temperature. In this study, we introduce a ballistic rectifier that resembles a diode bridge and is based on graphene encapsulated using hexagonal boron nitride. Our device's asymmetric geometry combined with the exploitation of the ratcheting effect means that it can operate successfully and provides excellent performance. The device's estimated responsivities at 38,000 V/W for holes and $23,000 \mathrm{~V} / \mathrm{W}$ for electrons at room temperature, are among the highest values for a ballistic device reported to date. Due to the device's zero threshold voltage, it is able to rectify Johnson noise signals converting thermal excitation to electrical energy at room temperature. The bandwidth of the device at the ballistic regime is estimated at $\sim 1.1 \mathrm{GHz}$ for holes and $2 \mathrm{GHz}$ for electrons. The device developed in this study is an important step along an innovative pathway that will lead to harvesting electrical energy directly from thermal energy.

\section{Full Text}

This preprint is available for download as a PDF.

\section{Supplementary Files}

This is a list of supplementary files associated with this preprint. Click to download.

- Supplementaryforblindreview.pdf 